\title{
EVALUASI STANDAR KOMPETENSI KERJA NASIONAL INDONESIA (SKKNI) SUB GOLONGAN PENANGKAPAN IKAN DI LAUT
}

\section{EVALUATION OF INDONESIA'S NATIONAL WORKING COMPETENCY STANDARD SUB GROUPS FISH CATCHING ON'THE SEA}

\author{
Fahmi Shidiq ${ }^{1}$, Tri W Nurani ${ }^{2}$, Roza Yusfiandayani ${ }^{2}$ \\ ${ }^{1}$ Program Studi Teknologi Perikanan Laut, Sekolah Pascasarjana \\ ${ }^{2}$ Departemen Pemanfaatan Sumberdaya Perikanan, \\ Fakultas Perikanan dan Ilmu Kelautan, Institut Pertanian Bogor \\ Korespodensi: asshidiqfahmi@gmail.com
}

\begin{abstract}
Competency standard for capture fisheries was esablished in 2013, this standard is supposed to be used as a reference in developing training program and competency assessment. After more than 5 year implementation, it was revealed that the application of the standard had some shortages. These are issue on its relevance to the actual working condition and some needed competencies were not accommodated in the standard (Nurani et al. 2017). To solve this problem, review should be carried out to the process of development and establishment of the standar. Research wascarried out in May-July 2018 with literature review, interviews, both qualitative and quantitative analysis in general. The results show the development and formation process of the standard was performed in accordance with the existing rules. Some issues identified from this process included: (1) acceptability and conformity to the actual working condition, (2) measurability and clarity of the texts, (3) the absence of master plan of competency standard development. (4) engagement of practicioners in standard development team, and (5) certification licences for all member of verification team. There are two priority actions needed to improve the quality of SKKNI development and forming process in the next, i.e. development of RIP SKKNI and increase engagement of practicioners in the process of standard development.
\end{abstract}

Keyword: author guidelines, Indonesian fisheries, policy journal

\begin{abstract}
ABSTRAK
SKKNI bidang perikanan tangkap golongan penangkapan ikan di laut sudah diterapkan sejak 2013, meskipun masih banyak kekurangannya. Beberapa kekurangan dari SKKNI diantaranya ketidaksesuaian standar dengan kondisi yang sebenarnya dan ada sejumlah kompetensi yang belum terakomodir dalam standar tersebut (Nurani et al. 2017). Permasalahan ini harus dicari solusinya, maka perlu dilakukan kajian untuk mengevaluasi proses pengembangan dan pembentukan standar ini. Penelitian telah dilakukan pada Mei-Juli 2018 melalui studi literatur, wawancara, serta analisis. Analisis mnggunakan pendekatan kualitatif (deskriptif) dan kuantitatif (skoring). Hasilnya menunjukkan bahwa pengembangan dan pembentukan SKKNI golongan penangkapan ikan di laut sudah sesuai aturan. Beberapa hal yang harus ditingkatkan/diperbaiki adalah meliputi (1) aseptebel serta kesesuaian dengan kondisi sesungguhnya, (2) terukur dan bahasa jelas, (3) tidak adanya Rancangan Induk Pengembangan (RIP) SKKNI, (4) komposisi praktisi pada tim perumus, dan (5) kepemilikan lisensi sertifikasi untuk seluruh tim verifikasi. Peningkatan kualitas SKKNI golongan perikanan laut kedepan ada 2 prioritas yaitu penyusunan RIP dan peningkatan keterlibatan pihak praktisi.
\end{abstract}

Kata kunci: penangkapan ikan laut, SKKNI, sumberdaya manusia 


\section{PENDAHULUAN}

Sumber Daya Manusia (SDM) merupakan semua pihak yang terlibat dalam suatu organisasi/kegiatan/program untuk mencapai tujuan awal yang telah ditetapkan (Hasibuan 2001). SDM diperlukan agar sumberdaya lain dapat dimanfaatkan untuk tujuan organisasi. Kompetensi yang dimiliki SDM tersebut akan menentukan kinerja organisasi (Ellitan 2002). Contoh dalam bidang penangkapan ikan, dimana kualitas ikan hasil tangkapan ikan sangat ditentukan oleh pengetahuan, keahlian, dan keterampilan nakhoda (Nurani et al. 2012). Kompetensi menjadi sangat penting bagi Indonesia karena termasuk bagian Masyarakat Ekonomi ASEAN (MEA), dimana barang, jasa, investasi, dan tenaga kerja akan bergerak mengalir di antara negaranegara peserta dengan hambatan yang kecil atau lebih bebas (Fadli 2014). Peningkatan kompetensi SDM dapat dilakukan melalui beberapa hal, mulai dari pendidikan formal sampai pendidikan informal seperti pelatihan-pelatihan yang dilanjutkan dengan sertifikasi sebagai pengakuan formal atas perbaikan kompetensi.

Kompetensi kerja SDM di Indonesia diatur dalam bentuk Standar Kompetensi Kerja Nasional Indonesia (SKKNI) yang dikoordinir oleh Kementerian Tenaga Kerja dan Transmigrasi (Kemnakertrans). Kompetensi SDM sektor Kelautan dan Perikanan dikoordinir oleh Kementerian Kelautan dan Perikanan (KKP). Standar kompetensi untuk sektor Perikanan Tangkap mencakup beberapa SKKNI. Salah satu di antaranya berupa Keputusan Menteri (Kepmen) Kemnakertrans RI No 298/2013 tentang Penetapan Standar Kompetensi Kerja Nasional Indonesia Kategori Pertanian, Kehutanan, dan Perikanan Golongan Penangkapan Ikan Sub Golongan Penangkapan Ikan di Laut. SKKNI ini menjadi dasar dalam sistem pelatihan dan sertifikasi yang bertujuan meningkatkan kompetensi kerja SDM perikanan tangkap.

SKKNI sub golongan penangkapan ikan di laut sudah seharusnya dijadikan rujukan pelatihan kerja dan sertifikasi profesi bidang penangkapan ikan. Namun fakta menunjukkan bahwa masih ada ketidaksesuaian antara kompetensi kerja pada SKKNI dan realisasinya. Beberapa kompetensi pada industri penangkapan ikan tidak terakomodasi di dalam SKKNI, padahal kenyataannya kompetensi itu dimiliki para nelayan dan dibutuhkan dalam industri penangkapan ikan seperti kompetensi Nakhoda Rawai Tuna di Palabuhan Ratu (Nurani et al. 2017). Oleh karen itu, perlu kajian terkait evaluasi pengembangan dan penyusunan SKKNI golongan penangkapan ikan di laut sebagai dasar pertimbangan dalam perbaikan di masa yang akan datang.

Kajian SKKNI pada bidang perikanan belum banyak dilakukan, berikut beberapa kajian yang pernah dilakukan (1) Kompetensi Nelayan Rawai Tuna Ditinjau dari Standar Kompetensi Kerja Nasional Indonesia (SKKNI) di Pelabuhan Perikanan Nusantara Palabuhanratu oleh Anugerah Y, Nurani TW, dan Sondita MFA, (2) Kompetensi Nakhoda Kapal Rawai Tuna di Palabuhanratu Ditinjau dari SKKNI oleh Nurani TW, Anugerah Y, dan Sondita MFA, dan (3) Strategi Peningkatan Kinerja Neyalan dalam Rantai Pasok Ikan Layur Melalui Pengembangan Model Insani di Pelabuhanratu oleh Retnowati H, Sukmawati A, dan Nurani TW. Semua kajian yang dilakukan menggunakan SKKNI sebagai dasar atau acuan, adapun kajian SKKNI perikanan belum pernah dilakukan. Maka kajian ini menjadi Kajian Evaluasi SKKNI perikanan pertama.

Tujuan penelitian meliputi (1) mengidentifikasi aturan yang berlaku dalam pengembangan dan proses penyusunan SKKNI, (2) menilai kesesuaian pengembangan dan proses penyusunan SKKNI sub golongan penangkapan ikan di laut dengan aturan yang berlaku, dan (3) menyusun rekomendasi perbaikan untuk pengembangan SKKNI perikanan tangkap di masa mendatang.

\section{METODE PENELITIAN}

Penelitian dilaksanakan pada bulan Mei-Juli 2018 bertempat di Kampus IPB Dramaga, Kementerian Kelautan dan Perikanan (KKP), Lembaga Sertifikasi Profesi (LSP) Kelautan dan Perikanan, dan Lembaga Sertifikasi Profesi (LSP) Kelautan. Jenis data yang digunakan yaitu data primer (melalui wawancara) dan sekunder (melalui studi literatur). Data primer diperoleh dari wawancara yang dilakukan pada 37 orang responden yang dianggap mewakili beberapa instansi, diantaranya Kemnakertrans, KKP RI, Lembaga Sertifikasi Profesi Kelautan dan Perikanan (LSP KP), LSP Kelautan, Tim Perumus dan Verifikasi, Pengusaha Penangkapan Ikan, Akademisi, dan Badan 
Pelatihan dan Penyuluhan Perikanan (BP3) Tegal, Ambon, dan Medan. Data primer difokuskan dalam melengkapi hasil studi literatur, mengkaji, dan mengevaluasi pengembangan dan proses penyusunan SKKNI sub golongan penangkapan ikan di laut.

Analisis data dilakukan secara bertahap sebagai berikut :

a. Aturan dasar pengembangan dan penyusunan SKKNI

Penelitian pertama ini dilakukan dengan studi literatur dan wawancara mendalam. Studi literatur dilakukan dengan mengkaji SKKNI mulai dari aturan berlaku, dasar pengembangan, dan proses penyusunannya. Selanjutnya dilakukan wawancara kepada perwakilan dari 3 institusi yaitu Perwakilan Pusat Pelatihan dan Penyuluhan Kelautan Perikanan (Puslatluh KP) KKP, Kemnakertrans RI, Lembaga Sertifikasi Profesi Kelautan dan Perikanan (LSP KP), Komite Standar Kompetensi Kelautan serta Perikanan (KSK KP) tahun 2013, dan Tim Perumus SKKNI sub golongan penangkapan ikan di laut untuk memperdalam serta mengkonfirmasi hasil kajian studi literatur.

b. Penilaian kesesuaian pengembangan dan penyusunan SKKNI golongan penangkapan ikan di laut

Metode yang dilakukan dalam penelitian tahap ini adalah wawancara mendalam dan penyebaran kuesioner. Hasil wawancara mendalam menjadi bahan dalam analisis kualitatif dengan metode deskriptif. Adapun hasil penyebaran kuesioner dijadikan dasar analisis kuantitatif dengan metode skoring. Metode skoring ini menggunakan skala likert dan diturunkan dalam penilaian kesesuai yang akan ditampilkan pada Tabel 1 dan Tabel 2. Adapun khusus untuk penilaian dasar pengembangan SKKNI secara format hanya dinilai dari sisi ada atau tidaknya dalam SKKNI sub golongan penangkapan ikan di laut.

c. Rekomendasi perbaikan pengembangan dan penyusunan SKKNI perikanan tangkap kedepannya

Penelitian tahap ketiga ini merupakan kelanjutan dari penelitian tahap 2 dengan mengkaji lebih dalam kekurangan yang ada pada pengembangan dan penyusunan SKKNI sub golongan penangkapan ikan di laut. Metode yang digunakan pada penelitian ini adalah studi literatur dan wawancara mendalam. Studi literatur dilakukan dengan mengkaji jurnal atau referensi lain untuk mengetahui sebab terjadinya dan mencari opsi perbaikan kedepannya. Adapun wawancara dilakukan untuk mengkaji informasi dari pihak yang terlibat dan mengetahui alasan terjadinya kekurangan itu. Kedua hasil dari studi literatur dan wawancara dianalisis untuk mendapatkan opsi perbaikan terbaik untuk pengembangan dan penyusunan SKKNI untuk kedepannya.

\section{HASIL DAN PEMBAHASAN}

\section{Aturan dasar pengembangan dan proses penyusunan SKKNI}

Pengembangan kompetensi SDM merupakan mandat dari Pancasila dan Undang-Undang Dasar (UUD) Negara Republik Indonesia Tahun 1945 dalam pengembangan manusia Indonesia seutuhnya dan masyarakat Indonesia seluruhnya untuk menuju masyarakat yang sejahtera, adil, makmur, dan merata. Kemudian mandat tersebut diturunkan dalam Undang-Undang (UU) RI No. 13/2003 tentang Ketenagakerjaan. Kemnakertrans sebagai koordinator standarisasi kompetensi secara nasional menetapkan Peraturan Menteri (Permen) Tenaga Kerja dan Transmigrasi No. 3/2016 (Revisi dari No. 8/2012) tentang Tata Cara Penetapan Standar Kompetensi Kerja Nasional Indonesia (SKKNI) dan No. 2/2016 (revisi dari No. 5/2012) tentang Sistem Standarisasi Kompetensi Kerja Nasional. Kedua Permen ini menjadi dasar dan panduan untuk proses penyusunanserta pengembangannya SKKNI termasuk golongan penangkapan ikan.

Proses penyusunan SKKNI secara umum melewati 3 tahap yaitu inisiasi, perumusan dan verifikasi, serta validasi dan penetapan. Secara waktu masingmasing tahap tidak diatur secara pasti, tetapi dengan adanya rencana tahunan perumusan maka diketahui bahwa target suatu SKKNI satu tahun mulai dari tahap pertama, kedua sampai ketiga. Adapun selengkapnya disajikan pada Gambar 1. 
Tabel 1. Skala likert penilaian kuesioner

\begin{tabular}{lc}
\hline \multicolumn{1}{c}{ Artinya } & Skor \\
\hline Tidak sesuai & 1 \\
Kurang sesuai & 2 \\
Cukup sesuai & 3 \\
Sesuai & 4 \\
Sangat sesuai & 5 \\
\hline
\end{tabular}

Tabel 2. Penilaian kesesuaian SKKNI

\begin{tabular}{cc}
\hline Interval & Kriteria \\
\hline $20-35$ & Tidak Sesuai Aturan \\
$36-51$ & Kurang Sesuai Aturan \\
$52-67$ & Cukup Sesuai Aturan \\
$68-83$ & Sesuai Aturan \\
$84-100$ & Sangat Sesuai Aturan \\
\hline
\end{tabular}

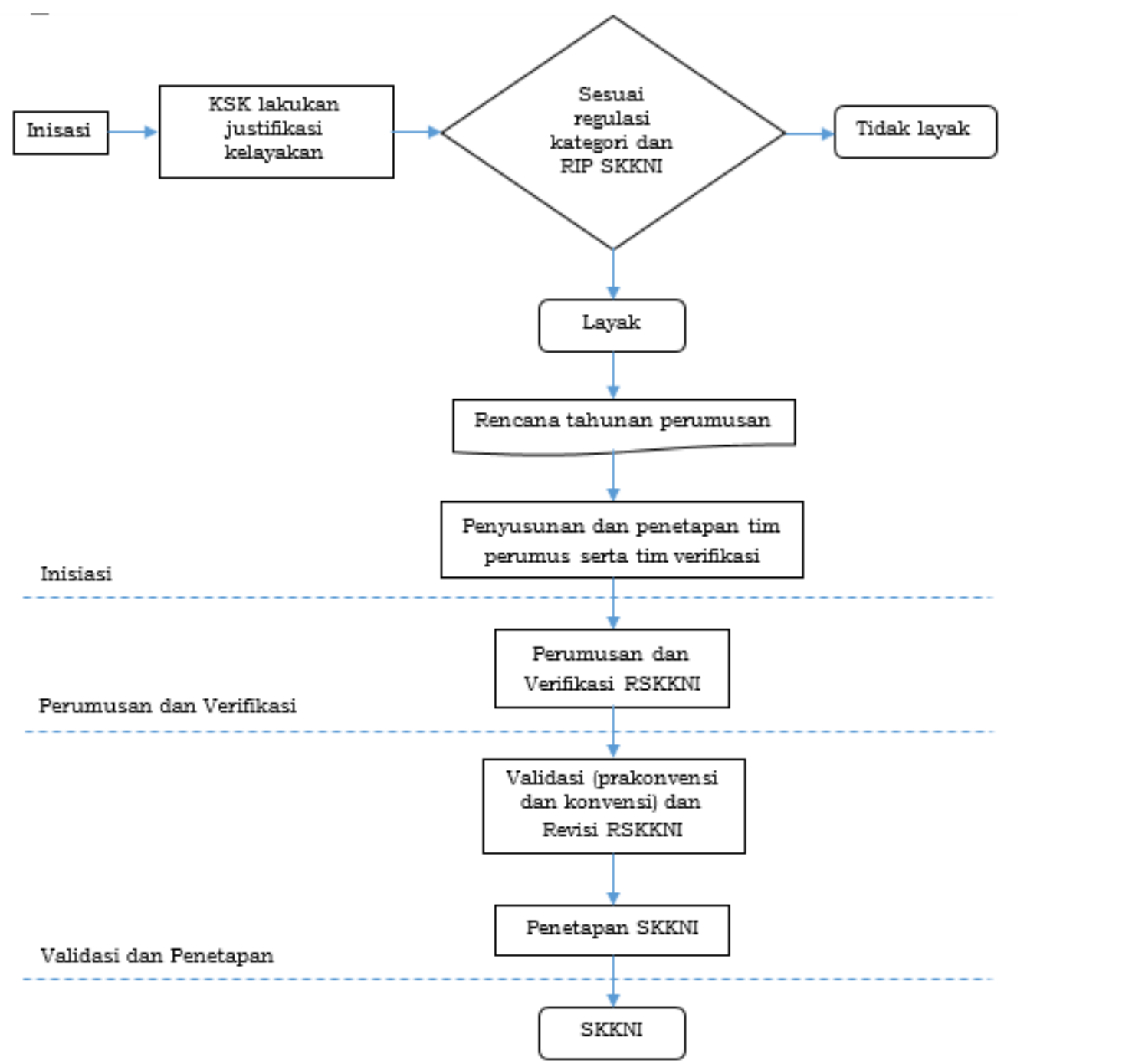

Gambar 1. Prosedur penyusunan SKKNI

Dasar pengembangan SKKNI secara umum bisa digolongkan ke dalam dua bagian yaitu dasar substansi dan format. Pada bagian dasar secara substansi pengembangan SKKNI dibagi menjadi tiga bagian yang masing-masing memiliki beberapa penurunan yang menjadi patokan yang harus dijaga saat penyusunan SKKNI. Sedangkan dasar secara format dibagi menjadi empat bagian kemudian masingmasing diturunkan dan empat bagian ini menjadi patokan dalam pengembangan format suatu SKKNI. Adapun selengkapnya disajikan pada Gambar 2. 


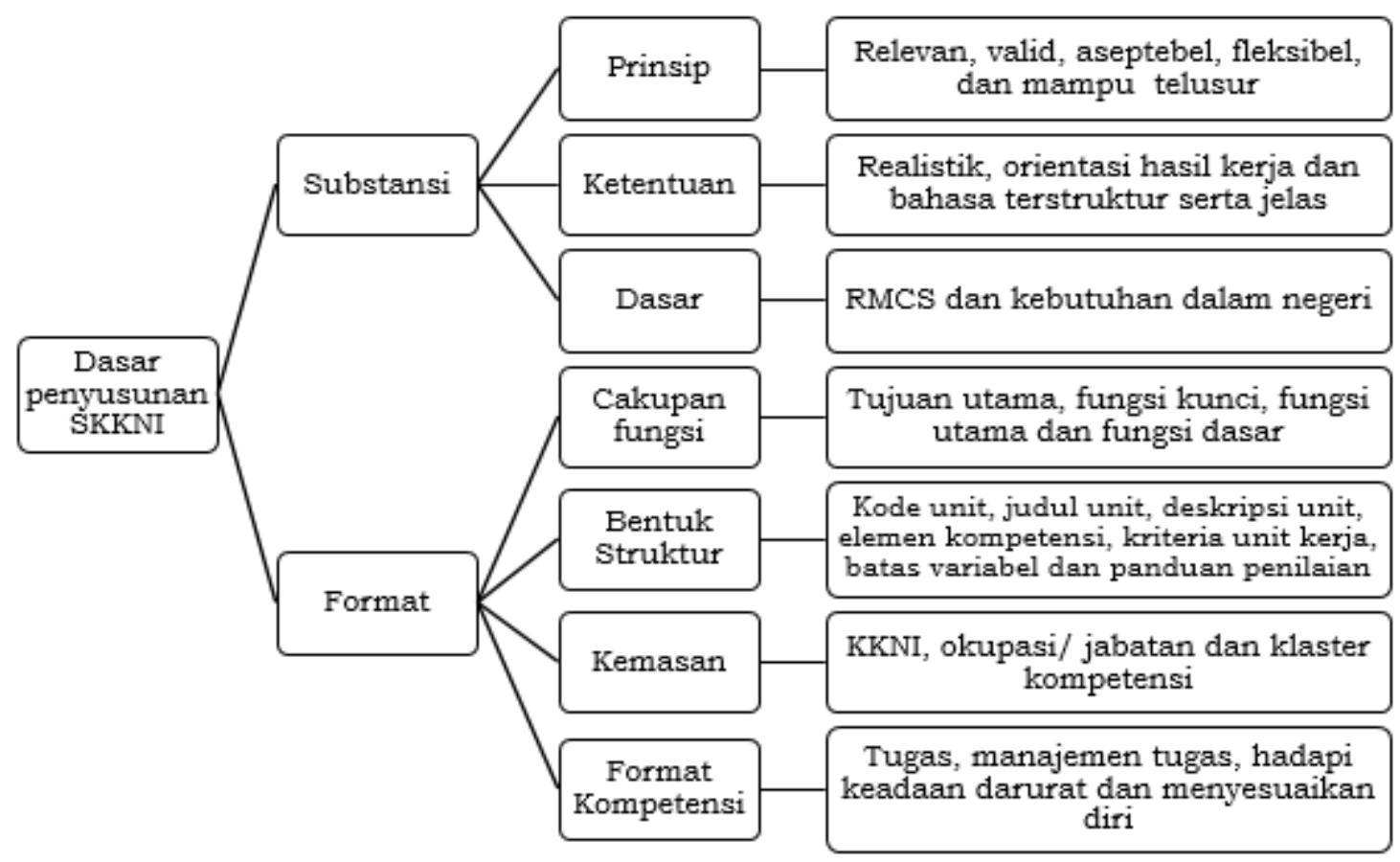

Gambar 2. Dasar pengembangan SKKNI

SKKNI golongan penangkapan ikan diinisiasi oleh Asosiasi Industri pada tahun 2011 dengan bentuk sebagai pengembangan dari SKKNI nautika perikanan laut yang disusun tahun 2005. Kemudian dikaji pada tahun November 2012 walau setelah itu tidak ada kelanjutannya, baru di tahun Mei 2013 dengan dibentuknya Komites Standar Kompetensi Kelautan dan Perikanan (KSK KP). Setelah itu proses penyusunan terus berprogres dengan sangat baik mulai dari penetapan Tim Perumus dan Tim Verifikasi di Juli 2013, dilanjutkan kajian perumusan dari verifikasi sekitar 1 bulan. Bulan Juli 2013 penyusunan mulai memasuki tahap validasi dengan diadakannya prakonvensi di Juli 2013, konvensi di September 2013 sampai ditetapkan dan disahkannya SKKNI golongan penangkapan ikan di November 2013. Adapun tahapan penyusunan SKKNI golongan penangkapan ikan dilaut selengkapnya disajikan pada Tabel 3.

Keterlambatan proses dari inisasi di 2011 sampai ada kelanjutan di 2012 dan baru mulai kembali 2013 disebabkan memang pada saat itu seluruh Kementerian belum mempunyai fokus pada pengembangan standar kerja. Bahkan pada 2013 hanya ada 1 Kementerian yang memiliki Rancangan Induk Pengembangan (RIP) SKKNI yaitu Kementerian Pertanian. Alasan kedua adalah Penetapan Komite Standar Kompetensi Kelautan dan
Perikanan (KSK KP) baru dilakukan pada Mei 2013. KSK KP adalah lembaga yang dibentuk oleh instansi teknis (KKP) dalam rangka membantu pengembangan SKKNI di sektor atau lapangan usaha Kelautan dan Perikanan golongan penangkapan ikan.

\section{Penilaian kesesuaian pengembangan dan penyusunan SKKNI sub golongan penangkapan ikan terhadap aturan yang ada}

Penilaian yang baik harus dilihat dari dua sisi yaitu dasar penilaian dan tim penilaian. Indikator yang digunakan berdasarkan pada aturan yang berlaku serta beberapa turunannya. Adapun tim penilainya dilakukan oleh tim ahli dan yang memiliki kemampuan dalam bidang SKKNI ini. Penilaian SKKNI sub golongan penangkapan ikan di laut dari segi dasar pengembangan secara substansi umumnya sudah sesuai dengan aturan yang ada. Walau ada tiga hal yang harus ditingkatkan yaitu aseptabel pada prinsip pengembangan yang bernilai 68 , pekerjaan realistik dan terukur serta bahasa jelas pada ketentuan pengembangan yang bernilai masing-masing 58 dan 52. Adapun penilaian kesesuian akan disajikan pada Tabel 4, 5, dan 6.

Semua dasar pengembangan secara format sudah terpenuhi dan ada dalam SKKNI sub golongan penangkapan 
ikan di laut. Hal ini menjadi sesuatu yang baik dan harus dipertahankan dalam penyusunan SKKNI selanjutnya. Walau dari sisi bentuk kemasan sudah ada perubahan kebijakan setelah dikelurakan revisi Permen Kemnakertras No.3/2016 tentang tatacara penetapan SKKNI.

Terakhir penilaian kesesuaian proses penyusunan SKKNI golongan penangkapan ikan terhadap aturan yang ada akan ditampilkan pada Tabel 6. Penilaian ini dilakukan dengan menurunkan beberapa indikator dari masing-masing tahap penyusunan SKKNI yang diambil dari aturan yang ada.

Kekurangan pada tahap inisasi adalah tidak adanya RIP SKKI Perikanan Tangkap. Adapun pada tahap perumusan dan verifikasi ada tiga hal yang harus ditingkatkan yaitu komposisi tim perumus dan tim verifikasi, keaktifan seluruh anggota tim dan yang paling harus diperbaiki syarat keahlian yang harus dimiliki tim perumus serta verifikasi.

\section{Rekomendasi perbaikan pengembangan dan penyusunan SKKNI perikanan tangkap}

Suatu sistem haruslah dievaluasi
secara berkala untuk mengetahui
kesalahan atau kekurangan yang terjadi,
dan mengambil tindakan perbaikan agar
tidak terulangi kedepannya. Hal ini berlaku
pula untuk pengembangan dan penyusunan
SKKN perikanan tangkap. Adapun
kekurangan (kurang sesuai indikator) pada
pengembangan dan penyusunan SKKNI
sub golongan penangkapan ikan dilaut
ditunjukan pada Tabel 7 .

Tabel 3. Tahap penyusunan SKKNI kategori perikanan tangkap

\begin{tabular}{|c|c|c|c|c|}
\hline No & Fase & Kegiatan & Tanggal & Keterangan \\
\hline \multirow[t]{4}{*}{1.} & Inisiasi & $\begin{array}{l}\text { Inisiasi SKKNI oleh } \\
\text { Asosisi Industri } \\
\text { Perikanan Tangkap }\end{array}$ & 2011 & $\begin{array}{c}\text { Tanggal, nama inisiator } \\
\text { dan penerima inisiasi tidak } \\
\text { diketahui }\end{array}$ \\
\hline & & $\begin{array}{l}\text { Kajian awal } \\
\text { penyusunan SKKNI }\end{array}$ & $\begin{array}{l}28 \text { November } \\
2012\end{array}$ & $\begin{array}{l}\text { Tercantum file draft RSKKNI } \\
\text { Bidang Penangkapan Ikan } 1\end{array}$ \\
\hline & & $\begin{array}{l}\text { Penetapan Komite } \\
\text { Standar Kompetensi } \\
\text { Bidang Kelautan dan } \\
\text { Perikanan (KSK KP) }\end{array}$ & 20 Mei 2013 & $\begin{array}{l}\text { Tanggal tercantum } \\
\text { dalam SKKNI Kategori } \\
\text { Penangkapan Ikan }\end{array}$ \\
\hline & & $\begin{array}{l}\text { Penyusunan dan } \\
\text { penetapan Tim } \\
\text { Perumus serta Tim } \\
\text { Verifikasi }\end{array}$ & 14 Juni 2018 & $\begin{array}{c}\text { Tercantum dalam } \\
\text { Keputusan KSK KP nomor } \\
\text { KEP.03/KOMITE-KP/2013 } \\
\text { dan KEP.04/KOMITE- } \\
\text { KP/2013 }\end{array}$ \\
\hline 2. & $\begin{array}{l}\text { Perumusan } \\
\text { dan Verifikasi }\end{array}$ & $\begin{array}{l}\text { Perumusan dan } \\
\text { Verifikasi }\end{array}$ & $\begin{array}{l}\text { Antara } 14 \text { Juni } \\
2013 \text { s.d } 30 \\
\text { Juli } 2013\end{array}$ & Tidak ada bukti pasti \\
\hline \multirow[t]{3}{*}{3.} & $\begin{array}{l}\text { Validasi dan } \\
\text { Penetapan }\end{array}$ & Prakonvensi & 31 Juli 2013 & $\begin{array}{l}\text { Bukti tercantum dalam } \\
\text { rekapan kehadiran } \\
\text { prakonvensi }\end{array}$ \\
\hline & & Konvensi & $\begin{array}{l}25 \text { September } \\
2013\end{array}$ & $\begin{array}{l}\text { Bukti tercantum dalam } \\
\text { rekapan kehadiran konvensi }\end{array}$ \\
\hline & & Penetapan SKKNI & $\begin{array}{l}10 \text { November } \\
2013\end{array}$ & $\begin{array}{l}\text { Bukti tercantum dalam } \\
\text { surat Keputusan Menteri } \\
\text { yang menetapkan SKKNI }\end{array}$ \\
\hline
\end{tabular}


Tabel 4. Penilaian dasar pengembangan SKKNI bidang penangkapan ikan secara substansi

\begin{tabular}{lccc}
\hline \multicolumn{1}{c}{ Indikator } & Kriteria & Skor & Kesesuaian \\
\hline Relevan & Berdasarkan Prinsip Pengembangan & & \\
Valid & Kebutuhan industri penangkapan & 92 & Sangat sesuai \\
Aseptabel & Aturan dasar berlaku & 96 & Sangat sesuai \\
Fleksibel & Diterima stakeholder & 68 & Sesuai \\
Mampu Telusur & Dapat diaplikasikan & 78 & Sesuai \\
\hline & Setara dengan SKKNI lain & 90 & Sangat sesuai \\
\hline Sesuai RMCS & Berdasarkan Dasar Kebijakan & & Sangat sesuai \\
Sesuai Kebutuhan & Kesesuaian dengan Permen Kemnakertras & 86 & Sangat sesuai \\
dalam Negeri & Kebutuhan industri penangkapan & 88 & San \\
\hline & Berdasarkan Ketentuan Pengembangan & & \\
\hline Pekerjaan Realistik & Sesuai di lapangan & 58 & Cukup sesuai \\
Orientasi Hasil Kerja & Ada targetan & 80 & Sesuai \\
Terukur dan bahasa & Terukur dan bahasa bisa dipahami & 82 & Cukup sesuai \\
jelas & & &
\end{tabular}

Tabel 5. Penilaian dasar pengembangan SKKNI bidang penangkapan ikan secara format

\begin{tabular}{|c|c|c|}
\hline Indikator & Kriteria & Kandungan \\
\hline \multicolumn{3}{|c|}{ Berdasarkan Cakupan Fungsi } \\
\hline Tujuan utama & Ada & Ada \\
\hline Fungsi kunci dari tujuan utama & Ada & Ada \\
\hline Fungsi utama dari fungsi kunci & Ada & Ada \\
\hline Fungsi dasar dari fungsi utama & Ada & Ada \\
\hline \multicolumn{3}{|c|}{$\begin{array}{l}\text { Berdasarkan Bentuk Struktur } \\
\end{array}$} \\
\hline Kode unit & Ada & Ada \\
\hline Judul unit & Ada & Ada \\
\hline Deskripsi unit & Ada & Ada \\
\hline Elemen kompetensi & Ada & Ada \\
\hline Kriteria unit kerja & Ada & Ada \\
\hline Batasan variabel & Ada & Ada \\
\hline Panduan penilaian & Ada & Ada \\
\hline \multicolumn{3}{|c|}{ Berdasarkan Bentuk Kemasan } \\
\hline KKNI & Ada & Ada \\
\hline Jabatan atau okupasi nasional & Ada & Ada \\
\hline Klaster kompetensi & Ada & Ada \\
\hline \multicolumn{3}{|c|}{ Berdasarkan Format Kompetensi } \\
\hline Kompetensi tugas & Ada & Ada \\
\hline Kompetensi manajemen tugas & Ada & Ada \\
\hline Kompetensi terhadap keadaan darurat & Ada & Ada \\
\hline Kompetensi dalam menyesuaikan diri & Ada & Ada \\
\hline
\end{tabular}


Tabel 6. Penilaian kesesuaian proses penyusunan SKKNI bidang penangkapan ikan

\begin{tabular}{|c|c|c|c|}
\hline Indikator & Kriteria & Skor & Kesesuaian \\
\hline \multicolumn{4}{|c|}{ Tahap Inisiasi } \\
\hline Inisiator & $\begin{array}{l}\text { (1) Instansi terkait (KKP RI), (2) } \\
\text { Masyarakat, (3) Asosiasi industri, (4) } \\
\text { Asosiasi profesi, (5) Lembaga sertifikasi } \\
\text { profesi, (6) Lembaga pendidikan vokasi/ } \\
\text { keterampilan, (7) Lembaga pelatihan } \\
\text { kerja, (8) Pemangku kepentingan } \\
\text { lainnya }\end{array}$ & 5 & Sangat sesuai \\
\hline $\begin{array}{l}\text { Berpanduan kepada } \\
\text { RIP SKKNI }\end{array}$ & RIP tidak ada tapi diputuskan KSK KKP & - & Tidak bisa dinilai \\
\hline $\begin{array}{l}\text { Alur proses pasca } \\
\text { ada insiasi }\end{array}$ & $\begin{array}{l}\text { KSK- > membuat keputusan -> } \\
\text { membentuk tim perumus dan verifikasi }\end{array}$ & 4 & Sesuai \\
\hline Pihak terlibat & KSK KKP & 5 & Sangat sesuai \\
\hline \multicolumn{4}{|c|}{ Tahap Perumusan dan Verifikasi } \\
\hline $\begin{array}{l}\text { Komposisi tim } \\
\text { perumus dan tim } \\
\text { verifikasi }\end{array}$ & $\begin{array}{l}\text { (1) pemerintah, (2) perwakilan industri, } \\
\text { (3) persatuan buruh, (4) akademisi }\end{array}$ & 3 & Cukup sesuai \\
\hline $\begin{array}{l}\text { Keaktifan seluruh } \\
\text { anggota tim }\end{array}$ & Semua aktif terlibat & 3 & Cukup sesuai \\
\hline $\begin{array}{l}\text { Progres perumusan } \\
\text { dan verifikasi }\end{array}$ & Berjalan lancar dan berprogres & 4 & Sesuai \\
\hline $\begin{array}{l}\text { Syarat keahlian } \\
\text { (lisensi) yang harus } \\
\text { dimiliki tim verifikasi } \\
\text { dan perumus }\end{array}$ & Beberapa tidak memiliki lisensi & 2 & Kurang sesuai \\
\hline \multicolumn{4}{|c|}{ Tahap Validasi dan Penetapan } \\
\hline $\begin{array}{l}\text { Pelaksanaan } \\
\text { prakonvensi }\end{array}$ & $\begin{array}{l}\text { Jumlah kehadiran peserta dan } \\
\text { keterwakilan berbagai kalangan yang } \\
\text { mengikuti }\end{array}$ & 5 & Sangat sesuai \\
\hline $\begin{array}{l}\text { Pelaksanaan } \\
\text { konvensi }\end{array}$ & $\begin{array}{l}\text { Jumlah kehadiran peserta dan } \\
\text { keterwakilan berbagai kalangan yang } \\
\text { mengikuti }\end{array}$ & 5 & Sangat sesuai \\
\hline Penetapan SKKNI & $\begin{array}{l}\text { Berjalan lancar dan berprogres dengan } \\
\text { baik }\end{array}$ & 4 & Sesuai \\
\hline
\end{tabular}

Tabel 7. Kekurangan pada proses pengembangan dan penyusunan SKKNI sub golongan penangkapan ikan

\begin{tabular}{cllllll}
\hline Bagian & \multicolumn{1}{c}{ Sub Bagian } & \multicolumn{2}{c}{ Indikator } & \multicolumn{2}{c}{ Penilaian } \\
\hline \multirow{2}{*}{ Penyusunan } & \multirow{2}{*}{ Inisiasi } & Berpaduan pada & RIP & Tidak ada & RIP \\
& & SKKNI & SKKNI & & \\
Penyusunan & Perumusan dan verifikasi & $\begin{array}{l}\text { Syarat keahlian (lisensi) } \\
\text { yang harus dimiliki tim } \\
\text { perumus dan tim verifikasi }\end{array}$ & Kurang sesuai \\
& & & & \\
\hline
\end{tabular}


RIP SKKNI adalah dokumen rencana program pengembangan SKKNI yang disusun oleh KKP. Pada 2013 masih banyak Kementerian yang tidak memiliki RIP SKKNI selain dari KKP. Sehingga pertimbangan yang digunakan dalam pengembangan dan penyusunan SKKNI serta panduan dalam inisiasi hanya pandangan serta keputusan dari KSK Kelautan dan Perikanan. Maka pembuatan RIP SKKNI menjadi hal penting dan harus menjadi prioritas bagi KKP. Ada beberapa tim verifikasi belum memiliki lisensi verifikasi, tetapi tetap dimasukkan karena keterbatasan SDM di KKP dan dinilai memiliki kemampuan dalam verifikasi. Hal ini dapat dimaklumi untuk penyusunan tahun 2013, tetapi tidak untuk kedepannya. Adapun hal yang harus ditingkatkan (bernilai cukup sesuai) pada proses pengembangan dan penyusunan SKKNI sub golongan penangkapan ikan dilaut ditunjukkan pada Tabel 8.

Salah satunya yang diduga menjadi penyebab empat indikator pada Tabel 8 tidak memiliki nilai yang sesuai adalah kurangnya keterlibatan pihak praktisi dalam penyusunan SKKNI dan dominasi pihak birokrat serta akademisi. Adapun praktisi yang dimaksud adalah asosiasi industri serta persatuan pekerja/buruh. Keterlebitan praktisi diharapkan akan tumbuhkan rasa kepemilikan karena ikut dilibatkan dalam penyusunan SKKNI, serta kementerian bisa lebih menghemat anggaran. Hal ini didukung penelitian Nurani et al. (2017) yang menyimpulkan bahwa masih ada gap antara kompetensi pada SKKNI dengan kompetensi yang dimiliki nelayan sebenarnya.

Tabel 8. Proses pengembangan dan penyusunan SKKNI sub golongan penangkapan ikan di laut

\begin{tabular}{|c|c|c|c|}
\hline Bagian & Sub Bagian & Indikator & Penilaian \\
\hline Pengembangan & Ketentuan Pengembangan & Pekerjaan realistik & Cukup sesuai \\
\hline Pengembangan & Ketentuan Pengembangan & Terukur dan bahasa jelas & Cukup sesuai \\
\hline Penyusunan & Perumusan dan verifikasi & $\begin{array}{l}\text { Komposisi tim perumus dan } \\
\text { tim verifikasi }\end{array}$ & Cukup sesuai \\
\hline Penyusunan & Perumusan dan verifikasi & $\begin{array}{l}\text { Keaktifan seluruh anggota } \\
\text { tim }\end{array}$ & Cukup sesuai \\
\hline
\end{tabular}

\section{KESIMPULAN DAN SARAN}

\section{Kesimpulan}

Aturan dasar dalam pengembangan dan penyusunan SKKNI terdiri atas Kepmen Kemnakertrans RI No. 2 dan 3/2016 yang merupakan revisi aturan di 2012. Dasar pengembangan SKKNI dibedakan menjadi dua yaitu dasar substansi dan format. Pengembangan dan proses penyusunan SKKNI sub golongan penangkapan ikan di laut secara umum sudah sesuai dengan aturan yang berlaku, walaupun ada dua hal yang kurang sesuai (harus diperbaiki) dan empat lagi hanya cukup sesuai (harus ditingkatkan). Adapun tiga hal prioritas yang harus dilakukan KKP untuk pengembangan dan penyusunan SKKNI meliputi penyusunan RIP SKKNI, peningkatan keterlibatan pihak praktisi (asosiasi industri dan persatuan buruh/ pekerja) serta memastikan semua tim perumus dan tim verifikasi memiliki lisensi yang sesuai.

\section{Saran}

Perlu evaluasi pengaplikasian SKKNI secara detail untuk melengkapi evaluasi dan kedepannya bisa digunakan sebagai rujukan dalam proses pembentukan dan pengembangan SKKNI.

\section{DAFTAR PUSTAKA}

Ellitan L. 2002. Praktik-Praktik Pengelolaan Sumberdaya Manusia dan Keunggulan Kompetitif Berkelanjutan. Jurnal Ekonomi Manajemen dan Kewirausahaan. 4(2): 65-76.

Fadli M. 2014. Optimasi Kebijakan Ketenagakerjaan dalam Menghadapi Masyarakat Ekonomi ASEAN 2015. Jurnal Rechts Vinding. 3(2): 281296.

Hasibuan S. 2001. Menejemen Sumber Daya Manusia Pendekatan Non Sekuler. Surakarta: Muhamadiyah University Press. 
[Kemnakertrans] Kementerian Tenaga Kerja dan Transmigrasi. 2012. Peraturan Menteri Tenaga Kerja dan Transmigrasi Republik Indonesia Nomor 5 tahun 2012 tentang Sistem Standarisasi Kompetensi Kerja Nasional. Jakarta (ID): Kemnakertrans.

[Kemnakertrans] Kementerian Tenaga Kerja dan Transmigrasi. 2012. Peraturan Menteri Tenaga Kerja dan Transmigrasi Republik Indonesia Nomor 8 tahun 2012 tentang Tata Cara Penetapan Standar Kompetensi Kerja Nasional Indonesia. Jakarta (ID): Kemnakertrans.

[Kemnakertrans] Kementerian Tenaga Kerja dan Transmigrasi. 2013. Keputusan Menteri Tenaga Kerja dan Transmigrasi Republik Indonesia Nomor 298 tahun 2013 tentang Penetapan Standar Kompetensi Kerja Nasional Indonesia Kategori Pertanian, Kehutanan, dan Perikanan Golongan Penangkapan Ikan Sub Golongan Penangkapan Ikan di Laut. Jakarta (ID): Kemnakertrans.

Nurani TW, Wisudo SH, Imron M. 2012. Implementasi Manajemen Mutu pada Industri Penangkapan Ikan. Marine Fisheries. 3(2): 103-113.

Nurani TW, Anugerah Y, Sondita MFA. 2017. Kompetensi Nakhoda Kapal Rawai Tuna di Palabuhanratu Ditinjau dari SKKNI. 8(1): 13-23.

Retnowati H, Sukmawati A, Nurani TW. 2014. Strategi Peningkatan Kinerja Neyalan dalam Rantai Pasok Ikan Layur Melalui Pengembangan Model Insani di Pelabuhanratu. Jurnal Manajemen IKM IPB. 9(2): 140-149

Undang-Undang Dasar Republik Indonesia Tahun 1945.

Undang-Undang Republik Indonesia Nomor 13 Tahun 2003 tentang Ketenagakerjaan. 